\title{
Economic benefits of fractional flow reserve utilization on intermediate lesions and its clinical impact after 1-year follow-up
}

\author{
Beneficio económico en la utilización de reserva fraccional de flujo en lesiones \\ coronarias intermedias y su impacto clínico a un año
}

\author{
Horacio A. Medina-de Chazal*, Fernando Cohen, Franco Pallavicini, Alejandro D. Fernández, \\ Carla R. Agatiello, and Daniel H. Berrocal \\ Department of Hemodynamics and Interventional Cardiology. Hospital Italiano, Buenos Aires, Argentina
}

\begin{abstract}
Background: Fractional flow reserve (FFR) is a proven technology for guiding percutaneous coronary intervention, but it is not reimbursed despite the fact that it frequently allows to defer revascularization. Our goal was to determine the economic benefit of FFR on intermediate lesions, as well as the clinical endpoints at 1-year follow-up. Methods: An observational prospective study that included consecutive patients with intermediate lesions evaluated with FFR between April 2013 and March 2016. For the economic analysis, we evaluated the specific resources used during the procedure. Clinical endpoints, including cardiovascular death, target lesion revascularization, and acute myocardial infarction, were followed up over a 1-year period. Results: FFR was performed on 222 lesions in 151 consecutive patients. FFR was positive in $26.1 \%$ of the assessed lesions. The estimated total cost using FFR was US\$ 891,290.08 while cost estimate without FFR was US\$1,557,352, meaning $43 \%$ in cost savings. There were one cardiovascular death and two readmissions during follow-up in the positive FFR group. Conclusion: FFR-guided revascularization on intermediate coronary lesions resulted in an economic benefit by reducing overall costs without harming clinical outcomes.
\end{abstract}

Key words: Coronary disease. Coronary interventions. Intermediate coronary lesions. Fractional flow reserve. Cost benefit. Argentina.

\section{Resumen}

Antecedentes: La reserva de flujo fraccional (FFR) es una herramienta con evidencia demostrada para guiar las angioplastias coronarias. El reembolso por los sistemas de cobertura de salud es parcial o nulo a pesar de frecuentemente diferir la angioplastia. Nuestro objetivo fue determinar el beneficio económico de la utilización del FFR en la evaluación de lesiones intermedias, y evaluar asimismo puntos finales clínicos en el seguimiento a un año. Métodos: Estudio observacional prospectivo que incluyó una cohorte de pacientes consecutivos con lesiones coronarias intermedias, evaluadas con FFR, entre abril de 2013 y marzo de 2016. Para el análisis económico se evaluaron los recursos específicos utilizados para la realización

\section{Correspondence:}

*Horacio A. Medina de Chazal

Tte. Gral. Juan Domingo Perón 4190, C.A.B.A

Date of reception: 14-11-2018

Date of acceptance: 10-12-2018

DOI: 10.24875/ACME.M20000066
Available online: $24-02-2020$ Arch Cardiol Mex (Eng). 2019;89(4):280-285 www.archivoscardiologia.com 
del procedimiento. Se analizaron puntos finales clínicos (muerte cardiovascular, revascularización de la arteria objetivo e infarto agudo de miocardio) durante la internación y en el seguimiento a un año. Resultados: Se incluyeron 222 lesiones en 151 pacientes consecutivos. Se registró FFR positivo en el $26.1 \%$ de las lesiones evaluadas. Se estimó que sin la utilización de FFR, 126 pacientes hubieran sido tratados con angioplastia transluminal coronaria y 25 con cirugía de revascularización miocárdica. El costo estimado con la utilización de FFR fue US\$ 891,290.08, mientras que sin el mismo hubiera sido de US\$ 1,557,352. Esto implicó un ahorro del $43 \%$ de los gastos. Se observaron una muerte de origen cardiovascular y dos reinternaciones en el grupo FFR positivo en el seguimiento a un año. Conclusiones: La revascularización de lesiones intermedias guiada por FFR resultó en un beneficio económico al reducir los costos generales sin resultar clínicamente perjudicial.

Palabras clave: Enfermedad coronaria. Intervenciones coronarias. Lesiones coronarias intermedias. Fracción de reserva de flujo coronario. Costo beneficio. Argentina.

\section{Introduction}

Coronary heart disease continues to be the leading cause of death worldwide ${ }^{1}$. Argentina is no exception: cardiovascular disease remains the leading cause of death, and it accounts for $32 \%$ of total cases ${ }^{2}$. Myocardial revascularization is both the surgical and percutaneous treatment of choice, with a higher usage rate in Western countries. Only in the USA, more than 1 million percutaneous coronary interventions or revascularization procedures are performed annually ${ }^{3}$.

In Argentina, according to a survey conducted in 2011 by the Organization for Economic Cooperation and Development Health Division, 942 percutaneous transluminal coronary angioplasties (CTA) are performed annually per million population, which is equivalent to approximately 38,000 annual angioplasties, a figure that, though far from numbers recorded in developed countries, is increasing.

Revascularization by means of CTA or coronary artery bypass grafting (CABG) plays an important role in the treatment of these patients, but both can have a paradoxical effect. In the presence of myocardial ischemia, revascularization reduces symptoms ${ }^{4,5}$ and improves the prognosis ${ }^{6-8}$, but in its absence, revascularization worsens the results ${ }^{9}$.

Cinecoronariography (CAG) is the gold standard for the diagnosis of coronary disease in epicardial coronary vessels, although the exact quantification of a lesion may be limited for different reasons. One of the main limitations is the difficulty to determine the actual diameter of the reference vessel when compared with the lesion under study ${ }^{10}$. Should it be with disease, as in patients presenting with diffuse coronary disease, the degree of stenosis caused by the lesion under study could be underestimated. In addition, the presence of contrast artifacts due to turbulence, shortening of some segments in different projections, calcifications, and ostial localization of lesions or bifurcations can contribute to assessment inaccuracy ${ }^{11}$. In addition, there is considerable interobserver variability at the time of evaluation ${ }^{12}$.

In Argentina, as in most places, the decision to revascularize is mainly made based on coronary lesions angiographic appearance, often not knowing if they are really causing myocardial ischemia: only $30 \%$ of patients undergoing angiographic assessment have a stress test with evidence of myocardial ischemia justifying their symptoms ${ }^{14,15}$. Even when said tests are available, they have various flaws. Graded exercise stress test (most commonly used test) has inadequate accuracy in various patients ${ }^{16}$; stress echocardiogram and single-photon emission computed tomography (SPECT) (tests with higher accuracy for ischemia identification) have limited capacity to define the localization of ischemia ${ }^{17}$, in addition to being expensive and limited in terms of availability. As a consequence, many coronary lesions that are not hemodynamically significant are unnecessarily subjected to CTA or CABG, with a considerable cost to the health system and to the detriment of the patient.

Fractional flow reserve (FFR) measurement is known to allow, in a simple, fast, and reproducible way, identification of functionally significant coronary lesions, with special benefit in intermediate coronary lesions (50-69\% stenosis). The previous studies showed that only $35 \%$ of these lesions have an FFR indicating the presence of ischemia ${ }^{18}$.

There is abundant evidence from randomized trials to demonstrate the clinical and economic benefit of the use of FFR in comparison with revascularization guided by angiography alone.

DEFER trial ${ }^{19}$ showed that there is no benefit in angioplasty of hemodynamically non-significant lesions determined by FFR measurement. The FAME trial $^{9}$ showed significant benefits in terms of morbidity and mortality in FFR-guided coronary lesions revascularization.

FFR-guided revascularization strategy also demonstrated a cost reduction ${ }^{9,20}$, which could mean a potential economic benefit for the health system. 
Table 1. Population characteristics ( $n=151$ )

\begin{tabular}{|l|c|}
\hline Variable & Value (\%) \\
\hline Age (mean \pm SD) & $69.22 \pm 11.1$ years \\
\hline Male gender & $92(60.92 \%)$ \\
\hline Current smoker & $21(14 \%)$ \\
\hline Diabetes & $39(26 \%)$ \\
\hline Hypertension & $111(74 \%)$ \\
\hline Dyslipidemia & $93(62 \%)$ \\
\hline $\begin{array}{l}\text { Known coronary heart } \\
\text { disease }\end{array}$ & $68(45.3 \%)$ \\
\hline Extracoronary vascular disease & $32(21.3 \%)$ \\
\hline Previous ATC & $50(33.3 \%)$ \\
\hline Previous CABG & $7(4.6 \%)$ \\
\hline Previous cardiac surgery & $4(2.6 \%)$ \\
\hline other than CABG & $11(7.3 \%)$ \\
\hline Previous oral anticoagulation & $101(67.3 \%)$ \\
\hline Hospitalized & $6[9.3 \%]$, GXT 6 [9.3\%]) \\
\hline Stress test positive result & $\begin{array}{l}\text { stres } \\
\text { strect }\end{array}$ \\
\hline
\end{tabular}

CTA: coronary transluminal angioplasty; CABG: coronary artery bypass graft; GXT: graded exercise stress test; SPECT: single-photon emission computed tomography.

FFR measurement systems have been available in Argentina for almost 10 years; however, it is an underutilized method in daily practice. The coverage of this procedure by social and prepaid health services is limited; thus, despite its potential savings in economic terms, current reality discourages its use.

Considering the increasing number and complexity of coronary interventions in Argentina, the potential economic savings through FFR implementation to guide revascularization in intermediate coronary lesions, in comparison with angiographic evaluation, might be relevant for the health system.

The purpose of this study was to determine the economic benefit of the use of FFR in the assessment of intermediate lesions and its clinical impact over a 1-year follow-up.

\section{Materials and methods}

A prospective observational study was conducted, which included a cohort of consecutive patients who showed intermediate coronary lesions in angiography that was assessed with FFR between April 2013 and March 2016. An intermediate or moderate coronary lesion was defined as luminal stenosis between 50 and $69 \%$ as assessed by angiography. A value of $<0.80$ was taken as positive $\mathrm{FFR}^{9}$, after obtaining maximum hyperemia with intracoronary adenosine infusion. Clinical characteristics of the study population and clinical and economic endpoints were analyzed during hospitalization and over a 1-year follow-up.

For the economic analysis, the specific resources used to perform the procedure were evaluated. PTCA costs were calculated taking into account all the resources used, both diagnostic and therapeutic, considering the value in the Argentinian market in the US dollars (USD), to avoid adjustments for oscillations in local currency during the analyzed period. The CAGB cost was considered according to the value of a previously established module that includes all the necessary resources, including the stay in the coronary care unit for 5 days.

Statistics of the department was reviewed for the evaluated period, and a utilization rate of 1.78 stents per patient was defined ( 0.51 conventional and 1.27 drug-eluting stents [DES]) and a mean of 1.1 days of stay in the coronary care unit per patient undergoing coronary angioplasty.

In addition, the endpoints were analyzed, which included cardiovascular death, revascularization of the target artery, and acute myocardial infarction, during the hospital stay and throughout the 1-year follow-up.

\section{Statistical analysis}

Categorical variables were reported as frequencies, while continuous variables were described by their mean and standard deviation or median and interquartile range.

\section{Results}

A total of 222 intermediate lesions were analyzed in the first 151 consecutive patients who underwent FFR in the period comprised between April 2013 and March 2016. The study population characteristics are summarized in table 1 . Of the included patients, only $42 \%$ had a positive stress test before the angiographic study, with SPECT being the most requested study (73.4\%). Non-ST-segment elevation acute coronary syndrome was the condition that more frequently motivated the performance of CAG (40\%) (Fig. 1). About $67.3 \%$ of the studies were carried out in inpatients. 


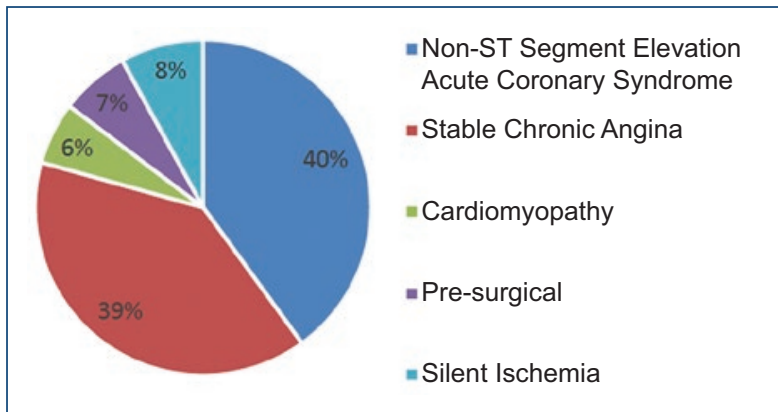

Figure 1. Diagnosis that motivated the coronary anatomy study. SCA: stable chronic angina; NSTE-ACS: non-STsegment elevation acute coronary syndrome.

Table 2. Distribution of the studied arteries $(n=199)$

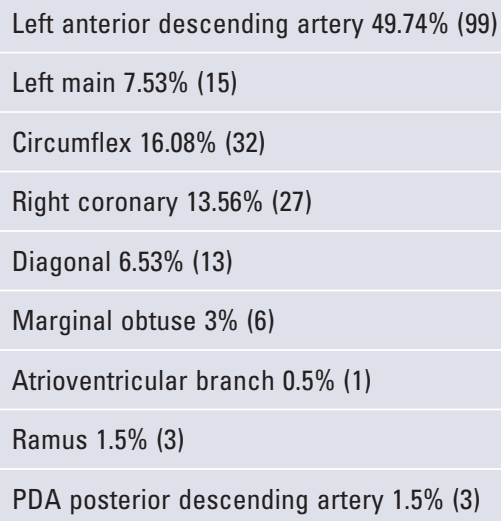

Among the assessed lesions, $26.1 \%$ yielded a value lower than 0.80 (58 lesions in 33 patients), with the anterior descending artery being the most commonly evaluated (49.74\%) (Table 2).

Of the 151 analyzed patients, 53 received percutaneous treatment, 12 surgical, and 86 medical treatment. Should FFR had not been used in the assessment of intermediate lesions, 126 patients would have undergone angioplasty and 25 CABG (Fig. 2). FFR measurement in intermediate lesions generated a saving of 141 stents (100.61 DES and 40.39 bare-metal stent, taking into account, the rate of stent use in the department) and 98.8 days of stay in the coronary care unit. In economic terms, should the measurement of this functional index not have been used, total cost would have been USD 1,557,352. With the FFR measurement, total amount was USD 891,290.08, which represented a saving of USD 666,061.92, or, expressed in relative terms, $42.77 \%$ (Fig. 3).

As for clinical events, there was a single cardiovascular death during the hospital stay in the FFR-positive group (patient with left ventricular thrombus, deceased from stroke waiting for $C A B G$ ). Three patients had to be readmitted for unstable angina during follow-up, two of them in the group that received angioplasty and one in the medical treatment group. Only one required a new angioplasty for restenosis of the stent implanted in the index event. Sixteen patients were lost to follow-up after the performance of the coronary angiography.

Among the analyzed patients, only two had serious complications related to the procedure (puncture site bleeding with transfusion requirement and coronary dissection during angioplasty, which required emergency CABG).

\section{Discussion}

The results of the present study show an economic saving in FFR-guided revascularization in comparison with standard angiography at the expense of a reduction in both percutaneous and surgical revascularization rates. This did not translate into clinical harm during hospitalization and during the 1-year follow-up. Although there was one death recorded in one of the groups, it was not caused by the diagnostic or therapeutic procedure, it was associated with chance.

As previously mentioned, angiography, despite being the reference standard in the assessment of intermediate lesions, is a poor predictor of ischemia-generating lesions. In the present study, an FFR value $>0.80$ was observed in $73.9 \%$ of studied lesions, which is consistent with findings reported in the literature. In the FAME trial ${ }^{9}$, $65 \%$ of intermediate lesions based on visual estimate showed an FFR $>0.80$ and $20 \%$ of stenosis, between 70 and $90 \%$, were not responsible for an FFR $<0.80$.

Frequently, the angiographic appearance of lesions that cause ischemia is identical to those that do not, and this is more marked in moderate lesions ${ }^{19}$. Demonstrating the presence of ischemia is crucial since it represents the most important predictor of adverse events in long-term follow-up ${ }^{8}$. Furthermore, angioplasty on non-ischemia-producing lesions has been documented not to be beneficial, and it can even be deleterious in terms of periprocedural complications and long-term follow-up, with a consequent increase in $\operatorname{costs}^{18}$. The use of FFR in this context optimizes clinical outcomes, with a decrease in both procedures - inherent risks and costs.

Despite the robust evidence about the benefits of FFR-guided angioplasty, this strategy is used in Argentina in a relatively low percentage, with one of the main reasons being its cost. Resources for the measurement 


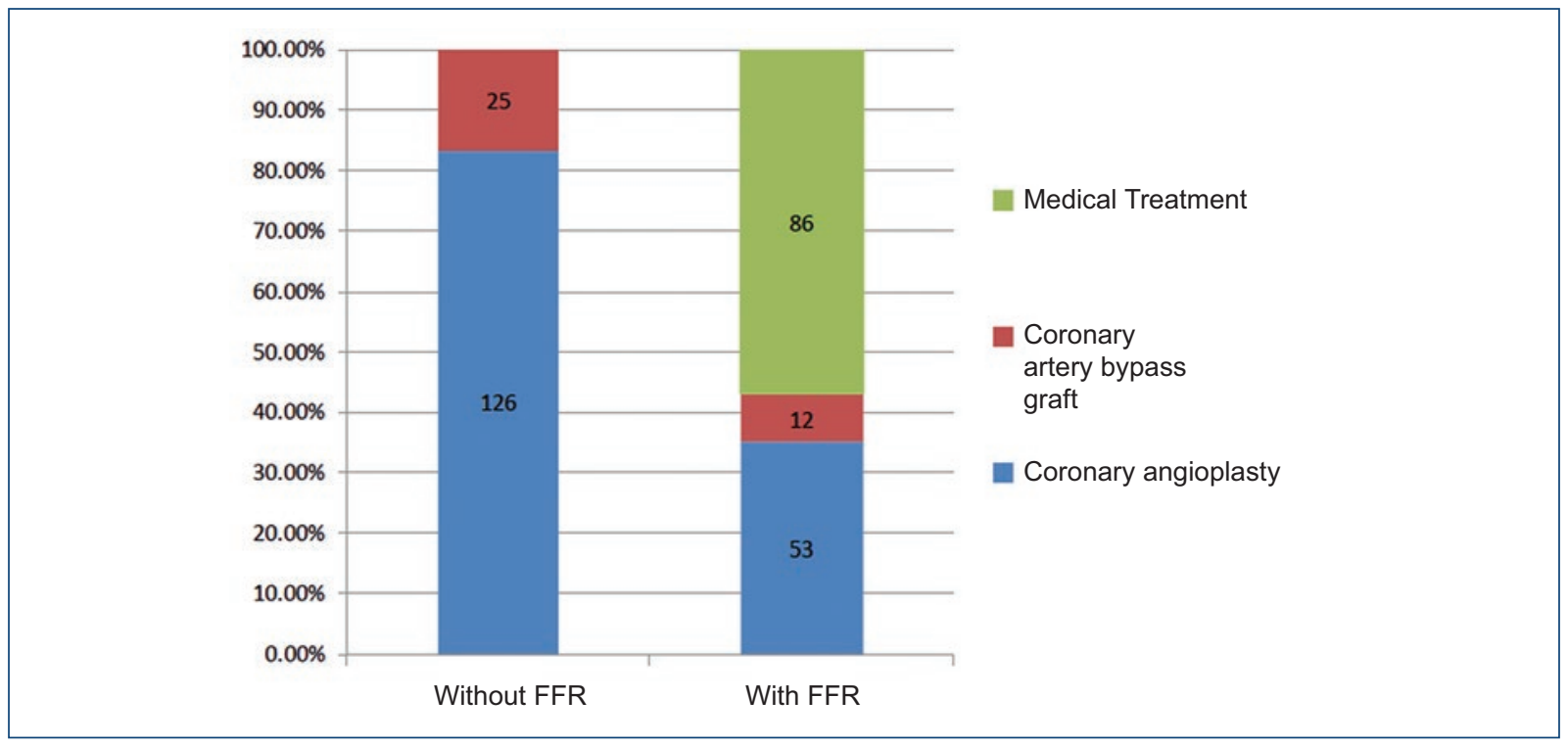

Figure 2. Differences between the proposed treatments without FFR measurement and after its measurement. CTA: coronary transluminal angioplasty; CABG: coronary artery bypass graft; FFR: fractional flow reserve.

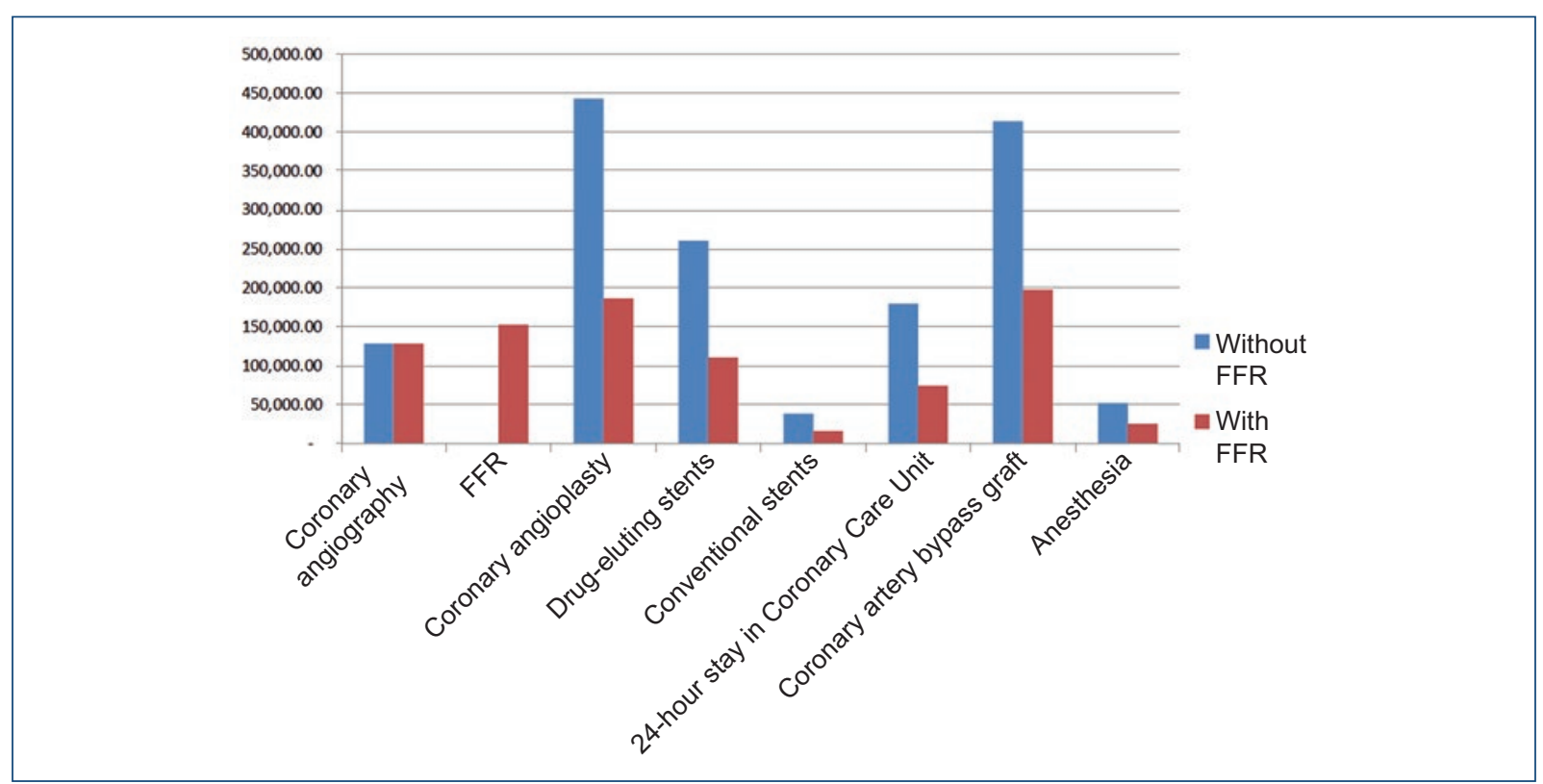

Figure 3. Cost difference (expressed in the US dollars) according to the use of FFR. CTA: coronary transluminal angioplasty; BMS: bare-metal stent; CAG: cinecoronariography; CABG: coronary artery bypass graft; DES: drug-eluting stent; FFR: fractional flow reserve.

of FFR are partially or not covered by the health system, which adds a non-recoverable cost to the budget of the various interventional cardiology centers. In contrast, health systems incur additional expenditure in terms of resources for revascularization and hospital stay that could be avoided.
Our economic analysis has limitations that we should mention. It represents a single-center study, the number of patients included in the study is relatively low and, not being randomized, the procedures and costs of the group without FFR were obtained from a calculation based on the rates of the usage of procedures and devices. 
The total number of both patients and intermediate lesions that are evaluated without prior evidence of ischemia in Argentina is unknown. For this reason, it is difficult to estimate the total potential economic impact of FFR generalized implementation.

Our analysis represents the economic evaluation during the hospital stay. According to some reports, this would be equivalent to approximately $90 \%$ of total cost per patient ${ }^{20}$. Some authors demonstrated, in a 1-year follow-up, a saving that can be as high as 30\% between both strategies total costs ${ }^{20}$. This means that there is a potential additional saving that was not assessed in the present work.

\section{Conclusion}

Routine implementation of an FFR-guided strategy in intermediate lesions generated an important change of behavior in terms of treatment, and in a group of patients that were scheduled for revascularization, it determined medical treatment ultimate implementation in a large part of them. This change of therapeutic behavior entailed a clear economic benefit without generating clinical harm for patients over a 1-year follow-up.

\section{Funding}

No sponsorship of any kind was received to carry out this study/article.

\section{Conflicts of interest}

The authors declare that they have no conflicts of interest.

\section{Ethical disclosures}

Protection of people and animal subjects. The authors declare that no experiments were performed on humans or animals for this study.

Confidentiality of data. The authors declare that no patient data appear in this article

Right to privacy and informed consent. The authors declare that no patient data appear in this article.

\section{References}

1. Nabel EG, Braunwald E. A Tale of Coronary Artery Diasease and Myocardial Infarction. N Engl J Med. 2012;366:54-63.

2. Indicadores Básicos, 2005. Disponible en: http://www.deis.msal.gov.ar/ wp-content/uploads/2018/04/indiba2005.pdf.

3. Rosamond, W, Flegal K, Friday G, Furie K, Go A, Greenlund K, et al. Heart disease and stroke statistics - 2007 Update: A report from the American Heart Association Statistics Committee and Stroke Statistics Subcommittee. Circulation. 2007:115(5):e69-171.

4. Pocock S. Coronary angioplasty versus medical therapy for angina: The second randomised intervention treatment of angina (RITA-2) trial. Lancet. 1997:350:461-8.

5. Finn SD, Gardin JM, Abrams J, Berra K, Blankenship JC, Dallas AP, et al. 2012 ACCF/AHA/ACP/AATS/PCNA/SCAI/STS Guideline for the Diagnosis and Management of Patients With Stable Ischemic Heart Disease: A Report of the American College of Cardiology Foundation/ American Heart Association Task Force on Practice Guidelines, and the American College of Physicians, American Association for Thoracic Surgery, Preventive Cardiovascular Nurses Association, Society for Cardiovascular Angiography and Interventions, and Society of Thoracic Surgeons. Circulation. 2012;126:e354-e471.

6. Erne $P$, Schoenenberger AW, Burckhardt D, Zuber M, Kiowski W, Buser PT, et al. Effects of Percutaneous Coronary Interventions in Silent Ischemia. JAMA. 2007;297:1985-91.

7. Shaw, LJ, Berman DS, Maron DJ, Mancini GB, Hayes SW, Hartigan PM, et al. Optimal medical therapy with or without percutaneous coronary intervention to reduce ischemic burden: results from the Clinical Outcomes Utilizing Revascularization and Aggressive Drug Evaluation (COURAGE) trial nuclear substudy. Circulation. 2008;117:1283-91.

8. Shaw LJ, Iskandrian AE. Prognostic value of gated myocardial perfusion SPECT. J Nucl. Cardiol. 2004;11:171-85.

9. Tonino P, De Bruyne B, Pijls N, Siebert U, Fumiaki I, van't Veer M. Fractional Flow Reserve versus Angiography for Guiding Percutaneous Coronary Intervention. N Engl J Med. 2009;360:213-24.

10. Topol E, Nissen S. Our Preoccupation With Coronary Luminology. Circulation. 1995;92: 2333-342.

11. Fischer JJ, Samady H, McPherson JA, Sarembock IJ, Powers ER, Gimple LW, et al. Comparison between visual assessment and quantitative angiography versus fractional flow reserve for native coronary narrowings of moderate severity. Am J Cardiol. 2002;90:210-5.

12. Zir L, Miller S, Dinsmore R, Gilbert J, Harthorne JW, et al. Interobserver variability in coronary angiography. Circulation 1976;627-32.

13. Boden W, O'Rourke R, Teo K, Hartigan P, Maron P, Kostuk W, et al. Optimal Medical Therapy with or without PCl for Stable Coronary Disease. N Engl J Med. 2007;356:1503-16.

14. Topol EJ, Ellis SG, Cosgrove DM, Bates ER, Muller DW, Schork NJ, et al. Analysis of coronary angioplasty practice in the United States with an insurance-claims data base. Circulation. 1993;87:1489-97.

15. Kern MJ, Donohue TJ, Aguirre FV, Bach RG, Caracciolo EA, Wolford T, et al. Clinical outcome of deferring angioplasty in patients with norma translesional pressure-flow velocity measurements. J Am Coll Cardiol. 1995;25:178-87.

16. Chest pain of recent onset: assessment and diagnosis. Clin. Guidel. [CG95]

17. Lima RS, Watson DD, Goode AR, Siadaty MS, Ragosta M, Beller GA, et al. Incremental value of combined perfusion and function over perfusion alone by gated SPECT myocardial perfusion imaging for detection of severe three-vessel coronary artery disease. J Am Coll Cardiol. 2003;42:64-70.

18. Pijls NH, van Schaardenburgh P, Manoharan G, Boersma E, Bech JW, van't Veer $\mathrm{M}$, et al. Percutaneous Coronary Intervention of Functionally Nonsignificant Stenosis. 5-Year Follow-Up of the DEFER Study. J Am Coll Cardiol. 2007;49:2105-11.

19. Bech GJ, De Bruyne B, Pijls NH, de Muinck ED, Hoorntje JC, Escaned J, et al. Fractional flow reserve to determine the appropriateness of angioplasty in moderate coronary stenosis: A randomized trial. Circulation. 2001;103:2928-34

20. Fearon WF, Bornschein B, Tonino PA, Gothe RM, Bruyne BD, Pijls NH, et al. Economic evaluation of fractional flow reserve-guided percutaneous coronary intervention in patients with multivessel disease. Circulation. 2010;122:2545-50. 